\section{TESTICULAR EPIDERMOID CYST}

A Case Report

\author{
Col KJ PHILIPOSE ${ }^{*}$ vSM, Maj N KANNAN ${ }^{+}$, \\ Wg Cdr V P BHALLA ${ }^{\sharp}$, Dr ASHISH KUMAR ${ }^{* *}$
}

\section{MJAFI 1998; 54 : 151-152}

KEYWORDS : Epidermoid cyst; Testicular conservation.

\section{Introduction}

$\mathbf{E}$ pidermoid cysts of the testes represent less than 1 per cent of all testicular tumours [1] . It affects young adults and is clinically characterised as a discreet testicular nodule. Differentiation from a testicular cancer is not easy. Till now , treatment of such a lesion has been an inguinal orchidectomy $[2,3]$. The case for testicular conservation in a young male with a benign testicular lesion is gaining ground in the recent years [3,4]. We report a case of testicular epidermoid cyst in a young male treated by testis sparing surgery.

\section{Case Report}

A 24-year-old male presented 2 months after noticing a progressively enlarging painless right testicular swelling. Physical examination revealed no loss of testicular sensation. The upper pole of right testis revealed a firm to hard, smooth one centimetre intratesticular nodule. The left testis was normal. Ultrasonography showed a single well demarcated cystic lesion in the upper pole of right testis.

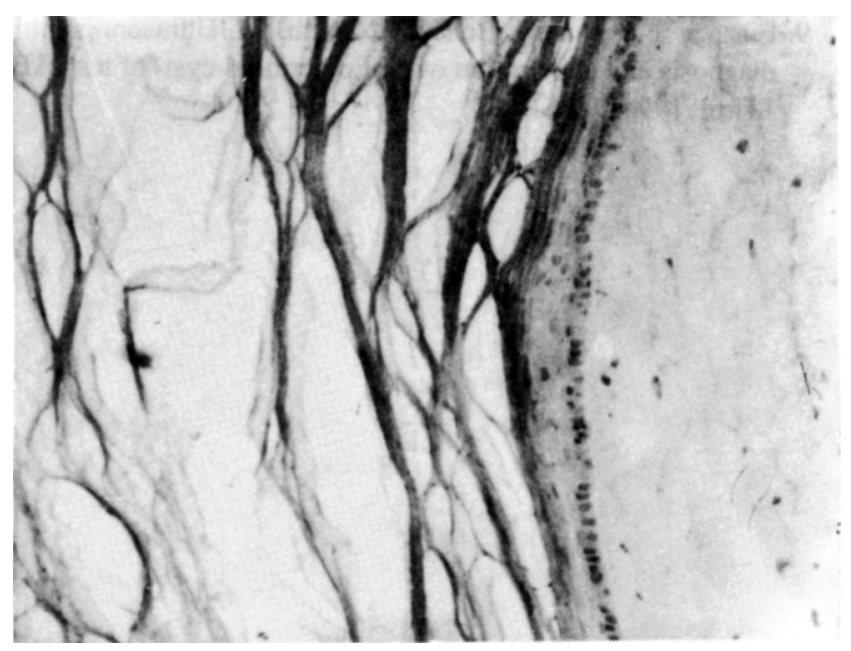

Fig. 1: Squamous lined epithelium with keratin and fibrous wall (x 50)
The patient was referred for a fine needle aspiration cytology, but a satisfactory aspirate could not be drawn. The testis was explored through an inguinal incision. The spermatic cord was occluded by a soft clamp at the deep ring and testis bivalved.

A smooth one $\mathrm{cm}$ diameter pearly white, globular well encapsulated cyst was enucleated out. Frozen section examination and paraffin slides revealed epithelium lined cystic lesion filled with putty like keratinous material (Fig 1). Adjacent testicular tissue showed normal spermatogenesis. No evidence of malignancy was noted in the cyst wall or adjacent testicular tissue (Fig 2).

\section{Discussion}

Epidermoid cysts of the testes was first reported by Dockerty and Priestly in 1942 [5]. To date about 300 instances of occurences are reported in medical literature [3]. The lesion commonly presents in the second to fourth decades of life as a discreet nodular lesion within the testis, which enlarges slowly and painlessly. Most of the lesions are solitary (86\%) and unilateral with an average diameter of $2 \mathrm{~cm}$. The right testis is involved more commonly than the left [2]. Testicular ultrasonography usually reveals a well demarcated

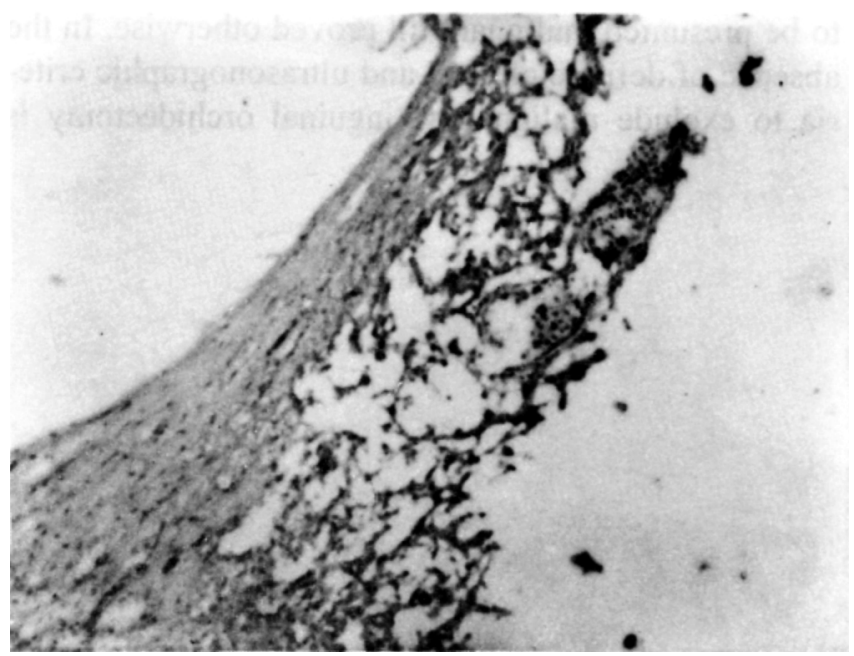

Fig. 2 : Fibrous wall of the cyst with normal testicular tissue outside the cyst.

\footnotetext{
"Senior Advisor (Surgery), Base Hospital, Delhi Cantt $110010{ }^{+}$Clinical tutor, ${ }^{*}$ Reader, "* Surgeon Trainee, Department of Surgery, Armed Forces Medical College, Pune 411040
} 
cystic or altered echogenic area. The investigative modality is fairly accurate in diagnosing the lesion in addition to providing information on multiplicity and bilaterality [6].

The most accepted theory on its origin is a strictly monomorphic ectodermal development of a teratoma along the lines of epidermal differentiation $[2,7]$. Pathologic criteria of a diagnosis as defined by Price (7) are:

a) cystic lesion strictly within the testicular parenchyma,

b) contains keratinized debris or amorphous material with cleft like spaces,

c) cyst wall composed of fibrous tissue with a complete or incomplete lining of squamous epithelium,

d) teratomatous elements or adnexal structures not present in cyst wall or adjacent testicular parenchyma,

e) cyst wall discreet and separate from tunica albugenia,

f) occasional lipogranulomatous inflammatory reaction with focal calcification.

Dieckmann and Loy in 1994 [8] have proposed 2 additional criteria to definitely exclude malignancy:

a) absence of placental alkaline phosphatase on immunohistochemistry,

b) absence of tubular intraepithelial neoplasia in adjacent testicular tissue.

There is no doubt that a mass lesion of the testis is to be presumed malignant till proved otherwise. In the absence of definite clinical and ultrasonographic criteria to exclude malignancy, inguinal orchidectomy is not an incorrect surgery to be advised.The undisputably benign nature of the lesion however makes orchidectomy appear an overkill. The consensus today favours testicular conservation. Exploration of the testis is carried out by the inguinal route and the decision to sacrifice the testis is reserved pending frozen section histopathology confirming malignancy $[1-5,8,9]$.

' It is important on frozen section to differentiate the lesion from mature teratomas and dermoid cysts which are to be treated by an inguinal orchidectomy.

\section{REFERENCES}

1. Mostofi F K and Price E B Jr. Tumours of the testes. In: Atlas of tumour pathology; Tumours of male genital system. Washington DC: Armed Forces Institute of Pathology. 1973; 1-7.

2. Shah K H ,Maxted W C , Chun B. Epidermoid cyst of testis. A report of three cases and an analysis of 141 cases from world literature. Cancer 1981, 47: 577-82.

3. Heidenreich A, Englemann V H, Vietsen H V, Derschum W. Organ preserving surgery in testicular Epidermoid cysts. J Urol (USA) 1995; 153: 1147-50.

4. Shenoy V, Treist W E, el-Bash O. Bilateral Epidermoid cyst of testes . A report of a case with preservation of one testis. J Urol 1995, 153: 1933-4.

5. Dockerty M D and Priestly J T. Dermoid cysts of the testes. J Urol 1942, 48: 392.

6. Shapeero L G and Vordermark JS. Epidermoid cyst of testes and role of ultrasonography. Urology 1993, 41: 75.

7. Price E B Jr. Epidermoid cysts of testes. A clinical and pathological analysis of 69 cases from testicular tumour registry. J Urol 1969, 102: 708-13.

8. Dieckmann K P, Loy V. Epidermoid cyst of testes : a review of clinical and histologenic considerations. Br J Urol 1994 , 73: 436-41.

9. Eustace S, GrahamD, Behan M, SmithJ M. Ultrasonographic diagnosis and enucleation of an Epidermoid cyst of testis. $\mathrm{Br}$ J Urol 1994, 74: 518-9. 